\title{
PELATIHAN KOMUNIKASI BAHASA INGGRIS DASAR BAGI MASYARAKAT RT.07/07 KELURAHAN WARAKAS TANJUNG PRIOK, JAKARTA UTARA
}

\author{
Gunawan Tambunsaribu \\ Universitas Kristen Indonesia \\ gunawanreza_tamsar@yahoo.com
}

\begin{abstract}
The writer, the doer of Social Service (PKM), has given a training with the theme "Basic English Pronunciation" for children in the sub-district named named Warakas, Tanjung Priok, North Jakarta. The main purpose of this service is to carry out a social service activities as one element of the Tridarma Perguruan Tinggi, three main tasks of universities. This social service is carried out by training the children to pronounce the uniqueness of English sounds, containing the sounds of fricative or affricative sounds $\left(\mid \theta /, / \partial /, 1 \int l_{1} / 3 /, / t \int l_{1} / d_{3} /\right)$. The participants, 25 participants, were very active and they responded to the material taught by the instructor well. The result of the survey taken from all the respondents are; 1) 94\% repondents said that the topics given by the trainers met their need; 2) 2) $96 \%$ of them said that they were easy to understand all the topics given to them; 3) 93\% repondents agreed that the topics they learned developed their spoken English; 4) $100 \%$ of the respondens said that all the trainers mastered the topics they gave to them; 5) $94 \%$ respondens agreed that all the trainers had interesting methods in teaching them; 6) $96 \%$ respondents said that all the trainers were friendly; 7) $100 \%$ respondents agreed to participate in the incoming training session; and 8) $80 \%$ of them suggested to have the grammar/tenses topics while $20 \%$ of them chose to get speaking lessons if there would be an incoming training sessions from the trainers.
\end{abstract}

Keywords: Social Service; Basic English Pronunciation; Tridarma Perguruan Tinggi; PkM

\begin{abstract}
Abstrak
Penulis sekaligus pelaksana PkM dalam hal ini telah melaksanakan pelatihan dengan tema pelafalan bunyi bahasa Inggris dasar (Basic English Pronunciation). Tujuan utama pelatihan ini adalah untuk meningkatkan keterampilan masyarakat melalui pelatihan komunikasi dasar kepada anak-anak yang berada di kelurahan Warakas RT. 07/07 Tanjung Priok, Jakarta Utara. Kegiatan PkM ini dilakukan dengan cara mengajak anak-anak belajar aktif melafalkan bunyi bahasa Inggris dasar. Metode palatihan adalah menggunakan beberapa sarana seperti ceramah, gambar, video dan bunyi bahasa Inggris dasar yang diputar melalui tape recorder atau tayangan di monitor LCD atau projektor. Pelafalan kosakata dasar bahasa Inggris dapat diajarkan dengan menuliskan kata-kata khusus yang mengandung bunyi unik bahasa Inggris seperti bunyi $(/ \theta /, / \partial /, / \mathrm{J} /, / \mathrm{t} / /, / \mathrm{d} 3 /)$.Peserta PKM yakni para siswa yang berjumlah 25 orang sangat aktif dan merespon materi yang diajarkan oleh pengajar. Dari hasil di atas maka dapat disimpulkan bahwa; 1) sebanyak 94\% peserta PkM mengatakan bahwa materi yang diberikan oleh pelaksana PkM sesuai dengan kebutuhan mereka; 2) sebanyak $96 \%$ responden mengatakan materi yang diberikan oleh pelaksana PkM mudah untuk mereka pahami; 3) 93\% responden mengatakan bahwa materi yang diberikan menambah kemampuan mereka dalam berbicara bahasa Inggris; 4) 100\% responden menyatakan bahwa pengajar menguasai materi yang diajarkan; 5) 94\% responden setuju bahwa pelaksana PkM mengajarkan materi dengan menarik; 6) sebanyak $96 \%$ mengatakan bahwa para pelatih bersikap ramah dan sopan saat memberikan pelatihan. 7) seluruh peserta pelatihan $(100 \%)$ mengatakan setuju jika pelatihan bahasa Inggris diadakan kembali, dan 8) sebanyak $80 \%$ menginginkan topik bahasan "grammar/tenses" untuk diberikan kepada mereka jika PkM terlaksana kembali sedangkan sebanyakk 20\% dari mereka memilih untuk mendapatkan topik 'berbicara/speaking'
\end{abstract}

Kata Kunci: Pengadian kepada Masyarakat; Pelafalan Dasar Bahasa Inggris; Tridarma Perguruan Tinggi; PkM

Submitted: 2020-09-03 $\quad$ Revised: $2020-09-18 \quad$ Accepted: 2020-09-20 


\section{Pendahuluan}

Tugas seorang dosen di pendidikan adalah tugas tri darma perguruan tinggi yaitu mendidik, meneliti dan mengabdi kepada masyarakat. PkM yang kepenjanganya adalah pengabdian kepada masyarakat adalah salah satu bagian yang tak bisa lepas dari dua tugas lainnya yakni mendidik dan meneliti. Tugas PkM adalah tugas mulia seorang pendidik termasuk dosen dalam mengembangkan dan memajukan kehidupan masyarakat dengan cara memberikan pelatihan keterampilan kepada masyarakat sesuai dengan bidang ilmu yang dimiliki seorang dosen, yakni bidang bahasa Inggris yang di dalamnya adalah keterampilan berkomunikasi dalam bahasa Inggris.

Komunikasi adalah proses penyampaian informasi dari satu orang ke orang yang lain (Griffin, 2004:105). Komunikasi adalah proses dimana informasi dipertukarkan dn dimengerti oleh dua orang atau lebih, biasanya dengan maksud untuk memotivasi, atau untuk mempengaruhi perilaku (Daft 2003 : 132).

Komunikasi dan Pendidikan memiliki peranan yang sangat penting dalam kehidupan manusia. Sejak lahir, manusia berkomunikasi serta memulai proses belajar dan itu akan terus berlangsung sepanjang hayat. Bahasa juga merupakan kunci penentu menuju keberhasilan dalam mempelajari semua bidang studi (Depdiknas:2004). Oleh karena itu, segala upaya harus dilakukan untuk menciptakan pembelajaran bahasa, khususnya bahasa Inggris, yang menyenangkan sehingga mampu memotivasi siswa dan masyarakat yang ingin meningkatkan kapasitas mereka belajar dan berkomunikasi secara lisan maupun tulisan.

Terkait makin tingginya peranan bahasa Inggris dalam era globalisasi sekarang ini, ditambah lagi sudah dimulainya MEA (Masyarakat Ekonomi ASEAN), komunikasi serta keterampilan berbahasa Inggris merupakan salah satu alat komunikasi sekaligus sebuah keterampilan yang semestinya harus dikuasai oleh masyarakat di negara manapun karena bahasa Inggris adalah bahasa penghubung dan pemersatu dalam lingkup internasional. Oleh sebab itu bahasa Inggris sudah ditetapkan menjadi bahasa Internasional.

Satu hal yang tak dapat dipungkiri adalah bahwa bahasa penguasaan Inggris belum menunjukkan hasil yang maksimal pada sebagian masyarakat Indonesia. Bahasa Inggris masih sering dianggap sebagai mata pelajaran dan alat komunikasi yang sangat sulit dan tidak menarik bagi mereka. Kesulitan dalam menguasai bahasa Inggris yang dialami banyak siswa di Indonesia adalah disebabkan oleh banyak faktor. Salah satu faktor penyebabnya adalah perbedaan pelafalan antara bahasa Indonesia dan bahasa Inggris.

Tambunsaribu (2020) dalam penelitiannya yang berjudul "Analisis Pelafalan Mahasiswa Dalam Melafalkan Irregular Verbs Bahasa Inggris" menyatakan bahwa sebagian masalah yang dihadapai para mahasiswa dalam mempelajari bahasa Inggris adalah masalah pelafalan. Dia menambahkan bahwa ada beberapa faktor yang mempengaruhi mahasiswa masih sulit melafalkan bahasa Inggris yakni a) perbedaan system bunyi antara bahasa Indonesia dan bahasa Inggris; b) inkonsistensi beberapa bunyi dalam bahasa Inggris; c) gangguan dari dialek daerah para siswa; dan karena d) bahasa Inggris memiliki silent letters sedangkan bahasa Indonesia tidak memilikinya.

Faktor lainnya yang secara umum menghambat kemajuan dalam Pembelajaran Bahasa Inggris yaitu:

a) Perbedaan system bunyi antara bahasa ibu dan bahasa asing. Moosa (1972) mengatakan bahwa siswa yang mempelajari bahasa Inggris yang bahasa ibunya adalah bahasa Arab mengucapkan kata-kata bahasa Inggris menyerupai bunyi kata bahasa ibu mereka (bahasa Arab). Alkhuli (1983) menyatakan bahwa masalah utama dalam mengajar dan belajar pelafalan bahasa Inggris adalah adanya perbedaan sistem suara/bunyi antara 
BERNAS:

Vol.1 No. 4, October 2020, pp. 375-384

bahasa Inggris dan bahasa asli pelajar sehingga seorang pelajar tersebut salah mengucapkan beberapa bunyi bahasa Inggris karena dia tidak menemukan bunyi tersebut dalam bahasa ibunya.

b) Inkonsistensi beberapa bunyi Dalam Bahasa Inggris. O'connor (2003) menyatakan bahwa tidak mudah untuk mengetahui bunyi yang tepat atas huruf-huruf yang ada dalam kata-kata tertentu. Power (2003) menemukan bahwa ada 23 masalah pengucapan umum, beberapa di antaranya terkait dengan huruf dan bunyi vocal.

c) Gangguan bahasa ibu dan pengaruh ejaan terhadap pengucapan. Moosa (1972) dan Swan \& Smith (2001) dalam penelitian mereka menyatakan bahwa bunyi /p/ dan /b/ adalah dua fonem yang berbeda dan masing-masing dibedakan oleh si penutur asli. Alkhuli (1983) menyatakan bahwa siswa negara Arab yang mempelajari bahasa Inggris bingung dengan bunyi /p/ dan /b/ karena pengaruh bahasa ibu, sehingga lidah mereka menjadi kaku saat melafalkan bunyi /p/ dan /b/, dan mereka melakukan kesalahan pelafalan bunyi tersebut sampai mereka menguasai bunyi bahasa Inggris (L2). Yule (1996) \& O'connor (2003) menyatakan bahwa masalah utama pelafalan bahasa Inggris adalah dengan membentuk kumpulan bunyi baru yang sesuai dengan suara bahasa Inggris, dan dengan merusak susunan bunyi bahasa Inggris tesebut karena kebiasaan dan sistem bahasa ibu (L1) sangat kuat pengaruhnya.

Tambunsaribu (2019) dalam bukunya berjudul "Say It: Keunikan Bunyi Bahasa Inggris" mengatakan bahwa banyak cara yang pelajar bahasa Inggris lakukan untuk belajar pengucapan bahasa Inggris yang baik dan benar. Dia mengatakan bahwa bagi orang Indonesia semestinya memahami adanya perbedaan unik antara bunyi bahasa Indonesia dan bahasa Inggris. Keunikan bunyi bahasa Inggris tersebut dapat menjadi modal awal kita untuk lebih cepat selangkah memahami bahasa Inggris.

Sejalan dengan tuntutan zaman terhadap semua orang yang mempersiapkan dirinya menuju dunia global, maka Fakultas Sastra UKI ingin turut ambil bagian dalam mempersiapkan masyarakat dari seluruh kalangan dalam menghadapi persaingan di dunia global sekarang ini dan yang akan datang dengan memberikan pelajaran komunikasi bahasa Inggris. Fakultas Sastra Universitas Kristen Indonesia (FS-UKI) memilih kegiatan pengajaran bahasa Inggris kepada para anak-anak di wilayah Warakas RT 07/07, Kelurahan Warakas Tanjung Priok, Jakarta Utara, dengan harapan dapat membekali para anak-anak tersebut untuk bersaing dalam menghadapi MEA (Masyarakat Ekonomi ASEAN) dan khususnya kepada para anak-anak di wilayah Warakas RT 07/07 yang masih duduk di bangku sekolah dalam menghadapi UN bahasa Inggris.

Adapun sasaran kegiatan mengajar bahasa Inggris ini ialah untuk anak-anak di wilayah RT 07/07, kelurahan Warakas, kecamatan Tanjung Priok, Jakarta Utara, DKI Jakarta. Kegiatan ini merupakan wujud pengabdian kepada masyarakat oleh Fakultas Sastra (FS) Universitas Kristen Indonesia, Jakarta. Kegiatan mengajar ini penting dilaksanakan, karena FS-UKI merupakan sebuah institusi pendidikan yang harus melaksanakan Tridarma Perguruan Tinggi, yang salah satunya adalah pengabdian kepada masyarakat. Selain itu, FS UKI juga peduli terhadap peningkatan kualitas SDM (Sumber Daya Manusia) dan pendidikan khususnya dalam bidang pelatihan keterampilan berbahasa Inggris. 


\section{Metode}

Maksud dari kegiatan ini adalah menjalin hubungan baik antara keluarga besar FS-UKI dengan masyarakat khususnya anak-anak di wilayah RT 07/07, kelurahan Warakas, kecamatan Tanjung Priok, Jakarta Utara. Dalam pelaksaan PkM ini, sasaran kegiatan adalah anak-anak pendidikan sekolah dasar (kelas 1 sampai dengan kelas 6 SD).

Metode kegiatan PkM ini adalah sebagai berikut:

1. Metode ceramah

Metode ini dilakukan dengan memberikan penjelasa tentang pentingnya keterampilan berkomunikasi dalam bahasa Inggris khususnya bagi para pelajar sekolah dasar yang telah mendapatkan pelajaran bahasa Inggris di sekolah masing-masing peserta PkM. Ceramah ini juga dilakukan merangsang pemikiran para peserta agar senantiasa mengembangkan dan meningkatkan kemampuan berbahasa apapun, khususnya bahasa Inggris, karena dengan komunikasi dengan penggunaan bahasa yang baik maka derajad dan mutu seseorang akan semakin meningkat pula di mata orang lain.

2. Metode Praktik Mengajar

Setelah memberikan penjelasan makna dan tujuan kegiatan PkM kepada para peserta PkM, metode yang dilakukan selanjutnya adalah melakukan praktik mengajar dan memberikan materi kepada para peserta. Metode pengajaran ini dilakukan dengan berbagai variasi.

a) Pertemuan pertama adalah dengan melatih peserta dengan ilmu dasar pelafalan bahasa Inggris yakni pengucapan bunyi alfabet disertai dengan contoh-contoh kosa kata yang dimulai dengan setiap huruf A sampai dengan Z. Contohnya:

A /ei $\rightarrow$ untuk kata Apple

$\mathrm{B} / \mathrm{bi} / \rightarrow$ untuk kata Bee, dan seterusnya untuk huruf sampai dengan alfabet akhir yakni huruf $Z$.

b) Pertemuan kedua dilanjutkan dengan memberikan peserta ilmu dan cara untuk terampil membaca huruf dengan huruf lainnya dalam bahasa Inggris. Karena pelafalan (pronunciation) bisa dibedakan menjadi dua, yaitu mengeja (spelling) dan membaca (reading). Mengeja adalah mengucapkan bunyi setiap huruf tanpa berdampingan dengan huruf lainnya, sedangkan kegiatan membaca adalah melafalkan bunyi sebuah huruf dengan bunyi huruf lainnya dalam sebuah kata.

Contoh 1:

A $\rightarrow$ dieja /ei/

A ditambah N menjadi "an" yang menjadi sebuah kata yang artinya 'sebuah' akan beda dari bunyi awal setiap huruf. A /eh/ dan $\mathrm{N} / \mathrm{n} / \rightarrow$ berbunyi /en/

\section{Contoh 2:}

$\mathrm{H} \rightarrow$ dieja /eitch/

$\mathrm{H}-\mathrm{A}-\mathrm{T} \rightarrow$ dibaca /het/

c) Pertemuan ketiga sampai pertemuan akhir

Di pertemuan ketiga sampai dengan pertemuan ke-10, peserta akan diberikan keterampilan untuk mengenal berbagai kosa-kata dasar dalam bahasa Inggris. Karena peserta adalah anak-anak sekolah dasar, mereka hanya diberkan ilmu dasar dalam melafalkan kosakata dasar seperti nama-nama warna (colors), angka 1 sampai dengan 100 (numbers), nama buah-buahan dan sayur-sayuran (fruits and vegetables), namanama dan jenis minuman dan makanan (food and drinks), nama-nama pakaian (clothes), 
BERNAS:

nama-nama hewan (animals), nama-nama dan jenis pakaian (clothes), nama-nama perasaan (feelings), nama-nama anggota tubuh (parts of body), serta tingkat kosakata menengah yakni nama-nama kegiatan (activities).

\section{3) Metode tanya jawab, diskusi, dan kuis}

Di setiap pertemuan, peserta akan diberikan kesempatan untuk bertanya jika mereka masih merasa bingung dan masih kurang memahami pelafalan atau pengucapan bunyi setiap kosakata yang sudah dipelajari dan dipraktekkan selama proses pelatihan. Setelah itu, setiap akhir pertemuan selalu diakhiri dengan memberikan kuis dan dalam setiap kuis diberikan hadiah kepada tiga peserta terbaik yang dapat melafalkan dengan baik dan benar setiap kosakata yang menjadi bahan kuis. Alasan diberikannya kuis di setiap akhir kegiatan adalah untuk memacu setiap peserta untuk tetap fokus dan giat belajar belajar selama proses pelatihan. Selain itu, para pelaksana PkM yakni dosen yang memberkan pelatihan dapat mengukur tercapainya tujuan kegiatan PkM yakni agar para peserta memiliki kemampuan dasar dalam melafalkan bunyi dasar bahasa Inggris.

\section{Hasil dan Pembahasan}

Kegiatan ini dimulai dengan rapat persiapan pelaksanaan PKM dengan ketua RT dan para kepala keluarga di RT 07/07 Warakas untuk menjalin komunikasi yang baik. Setelah itu akan ketua pelaksana dan para anggota akan mempersiapkan bahan atau materi PkM, dan dilanjutkan dengan pelaksanaan kegiatan belajar mengajar yang direncanakan dalam sepuluh kali pertemuan. Kegiatan ini akan diakhiri dengan pelaksanaan evaluasi dan penyusunan laporan pertanggungjawaban (LPJ). Pembagian waktu setiap uraian kegiatan adalah sebagai berikut:

a. persiapan pelaksanaan 10 jam

b. pelaksanaan kegiatan 20 jam (10x2 jam), dan

c. rapat persiapan dan akhir pelaksanaan PkM sebanyak 4 jam. Jadi total pelaksanaan PKM ini adalah selama 34 jam.

Kegiatan pelatihan ini setiap harinya diikuti oleh peserta sekitar 15 sampai dengan 25 orang. Sebagian besar adalah anak-anak yang berada di RT.07 dan sebagian ada yang dari RT.06 kelurahan Warakas. Pelatihan ini berjalan lancar. Kegiatan PkM ini sangat didukung oleh para orangtua peserta serta pemerintah daerah setempat. Mereka sangat menunjukkan respon yang positif dan berharap kegiatan PkM dapat terus dilanjutkan di wilayah mereka.

Pada kegiatan pelatihan ini, ada bebera faktor penghambat, diantaranya:

a. Waktu pelatihan dirasakan belum maksimal karena keterlambatan beberapa siswa yang masih bentrok waktunya beberapa menit karena harus belajar les mengaji terlebih dahulu.

b. Tempat pelaksanaan PkM kurang luas karena semakin hari peserta PkM semakin bertambah yang tadinya hanya ditargetkan untuk 20 orang anank saja tetapi selalu bertambah setiap harinya sehingga mencapai 30 0rang anak.

c. Sarana dan prasaran yang maksimal belum tersedia seperti projektor, laptop, dan koneksi internet sehingga pelaksana PkM masih memanfaatkan spidol dan papan tulis serta rekaman dari telepon genggam dalam melakukan pelatihan. 
1. Materi yang diberikan oleh kakak pengajar sesuai dengan kebutuhan saya.

2. Materi yang diberikan oleh kakak pengajar mudah untuk saya pahami.

3. Materi yang diberikan oleh kakak pengajar menambah kemampuan saya dalam berbicara bahasa Inggris.

4. Kakak pengajar menguasai materi yang diajarkan kepada saya.

5. Kakak pengajar mengajarkan materi dengan menarik.

6. Kakak pengajar ramah dan sopan saat mengajar.

Tabel 1. Bobot Nilai

\begin{tabular}{cl}
\hline Bobot Nilai & Keterangan \\
\hline 5 & SS (Sangat Setuju) \\
4 & S (Setuju) \\
3 & R (Ragu-ragu) \\
2 & TS (Tidak Setuju) \\
1 & STS (Sangat Tidak Setuju) \\
\hline
\end{tabular}

Perhitungan bobot nilai atas jawaban responden terhadap masing-masing pernyataan survey adalah sebagai berikut :

1) Responden yang menjawab sangat setuju $=\mathrm{SS} \times 5$

2) Responden yang menjawab setuju $=\mathrm{S} \times 4$

3) Responden yang menjawab netral $=\mathrm{N} \times 3$

4) Responden yang menjawab tidak setuju $=\mathrm{TS} \times 2$

5) Responden yang menjawab tidak sangat setuju $=$ STS $\times 1$

Total Skor $=$ SS + S + N + TS + STS

Tabel 2. Presentase Nilai

\begin{tabular}{ll}
\hline Jawaban & Keterangan \\
\hline $0 \%-19.99 \%$ & Sangat (Tidak Setuju, Buruk atau \\
& Kurang Sekali) \\
$20 \%-39.99 \%$ & Tidak Setuju atau Kurang Baik \\
$40 \%-59.99 \%$ & Cukup atau Netral \\
$60 \%-79.99 \%$ & Setuju, Baik atau Suka \\
$80 \%-100 \%$ & Sangat (Setuju, Baik, Suka) \\
\hline
\end{tabular}

Untuk mencari hasl interpretasi terhadap setiap pion survey, harus diketahui terlebih dahulu skor tertinggi dengan simbol $(\mathrm{X})$ dan nilai terendah dengan simbol $(\mathrm{Y})$.

$\mathrm{Y}=$ (skor tertinggi likert) $\mathrm{X}$ (jumlah responden) $=5$ (Angka tertinggi)

$X=($ Skor terendah likert) $X$ (jumlah responden) $=1$ (Angka terendah)

Index $\%=$ Total Skor $/ \mathrm{Y} \times 100$

Jumlah skor tertinggi untuk item SS (Sangat Setuju) adalah $5 \times 25=125$, sementara item STS (Sangat Tidak Setuju) adalah $1 \times 25=25$. Jadi, nilai $Y=125$ dan $X=25$

\section{Hasil}

1. Hasil survey poin 1: Materi yang diberikan oleh kakak pengajar sesuai dengan kebutuhan saya.

a. Hasil survey

SS: $17, \mathrm{~S}: 8, \mathrm{~N}: 0, \mathrm{TS}: 0, \mathrm{TSS}: 0$ 
BERNAS:

Total skor $=85+32+0+0+0=117$

b. Index Presentase $=$ Total Skor $/ \mathrm{Y} \times 100$

$=117 / 125 \times 100$

$=93.6 \%=94 \%$, Kategori "Sangat Setuju"

Dari hasil di atas maka dapat disimpulkan bahwa responden SANGAT SETUJU bawa materi yang diberikan oleh pelaksana PkM sesuai dengan kebutuhan para peserta.

2. Hasil survey poin 2: Materi yang diberikan oleh kakak pengajar mudah untuk saya pahami.

a. Hasil survey

SS: 21, S: 3, N: 1 , TS: 0 , TSS : 0

Total skor $=105+12+3+0+0=120$

b. Index Presentase $=$ Total Skor $/ \mathrm{Y} \times 100$

$=120 / 125 \times 100$

$=96 \%$, Kategori "Sangat Setuju"

Dari hasil di atas maka dapat disimpulkan bahwa para responden sangat setuju mengatakan materi yang diberikan oleh pelaksana PkM mudah untuk mereka pahami.

3. Hasil survey poin 3: Materi yang diberikan oleh kakak pengajar menambah kemampuan saya dalam berbicara bahasa Inggris.

a. Hasil survey

SS: 24, S: $1, \mathrm{~N}: 0$, TS: 0 , TSS : 0

Total skor $=120+4+0+0+0=124$

b. Index Presentase $=$ Total Skor $/ \mathrm{Y} \times 100$

$=124 / 125 \times 100$

$=99,2 \%=93 \%$, Kategori "Sangat Setuju"

Dari hasil di atas mengatakan bahwa para responden sangat setuju bahwa materi yang diberikan oleh pelaksana PkM menambah kemampuan mereka dalam berbicara bahasa Inggris.

4. Hasil survey poin 4: Kakak pengajar menguasai materi yang diajarkan kepada saya.

a. Hasil survey

SS: 25, S: $0, \mathrm{~N}: 0$, TS: 0 , TSS : 0

Total skor $=125+0+0+0+0=117$

b. Index Presentase $=$ Total Skor $/ \mathrm{Y} \times 100$

$=125 / 125 \times 100$

$=100 \%$, Kategori "Sangat Setuju"

Dari hasil di atas mengatakan bahwa para responden sangat setuju bahwa pelaksana/pengajar dalam pelasana PkM menguasai materi yang diajarkan kepada para peserta PkM. 
5. Hasil survey poin 5: Kakak pengajar mengajarkan materi dengan menarik.
a. Hasil survey

SS: $17, \mathrm{~S}: 5, \mathrm{~N}: 3, \mathrm{TS}: 0, \mathrm{TSS}: 0$

Total skor $=85+20+12+0+0=117$

b. Index Presentase $=$ Total Skor $/ \mathrm{Y} \times 100$

$=117 / 125 \times 100$

$=93.6 \%=94 \%$, Kategori "Sangat Setuju"

Dari hasil di atas mengatakan bahwa para responden sangat setuju bahwa para pengajar/pelaksana PkM mengajarkan materi kepada para peserta PkM dengan menarik.

6. Hasil survey poin 6: Kakak pengajar ramah dan sopan saat mengajar.

a. Hasil survey

SS: 20, S: 5, N: 0, TS: 0 , TSS : 0

Total skor $=100+20+0+0+0=120$

b. Index Presentase $=$ Total Skor $/ \mathrm{Y} \times 100$

$=120 / 125 \times 100$

$=96 \%$, Kategori "Sangat Setuju"

Dari hasil di atas mengatakan bahwa para responden sangat setuju bahwa para pelatih PkM bersikap ramah dan sopan saat mengajar peserta PkM.

Dari dua pertanyaan essay yang disertakan dalam survey, seluruh peserta pelatihan bahasa Inggris yakni sebanyak 25 orang (100\%) mengatakan setuju jika pelatihan bahasa Inggris diadakan kembali di kesempatan berikutnya di wilayah mereka. Sementara itu, sebanyak 20 orang (80\%) menginginkan topik bahasan "grammar/tenses" untuk diberikan kepada mereka jika PkM terlaksana kembali, sedangkan 5 orang $(20 \%)$ lainnya memilih untuk mendapatkan topik 'percakapan/berbicara'.

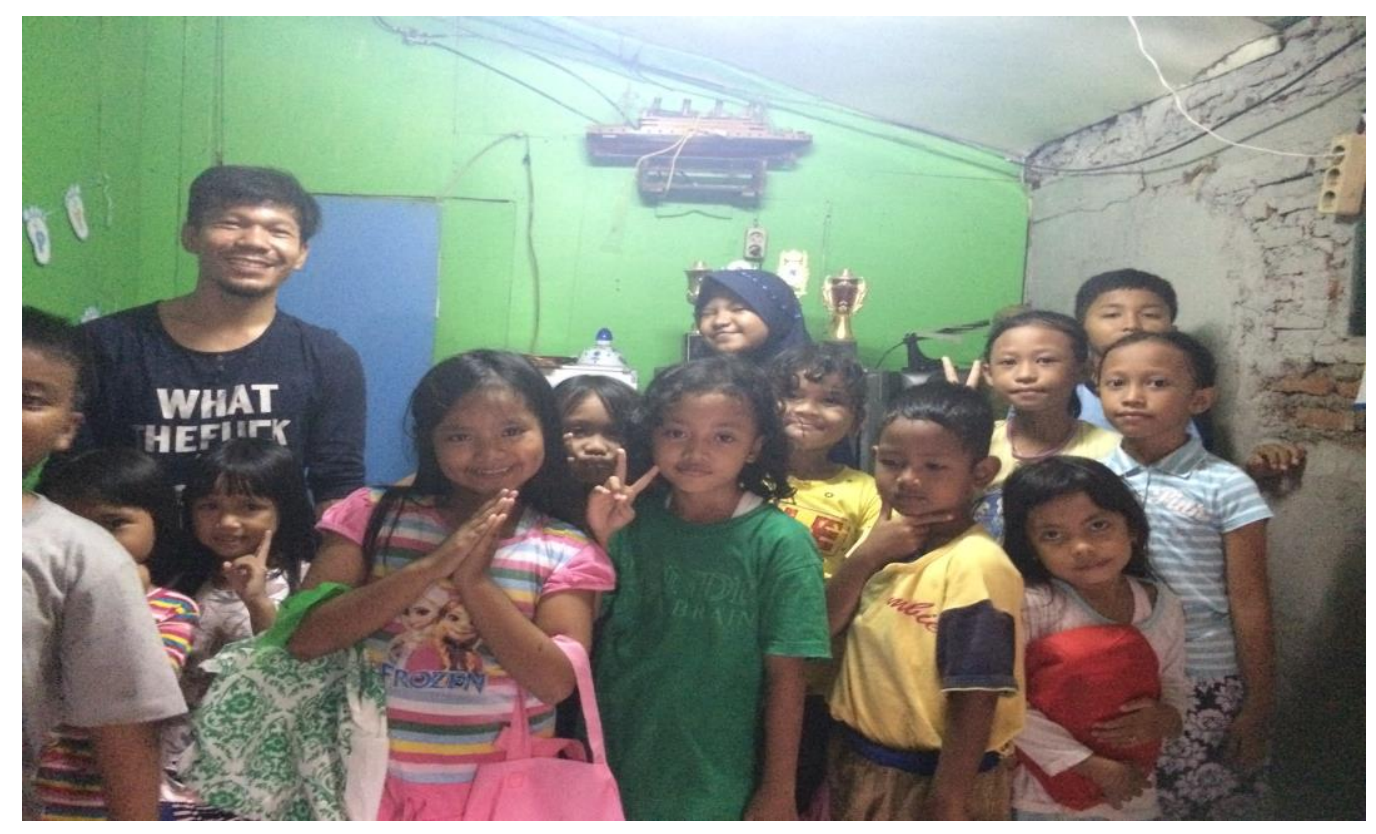

Gambar 1. Pelaksana PkM memberikan ceramah di awal pelatihan 


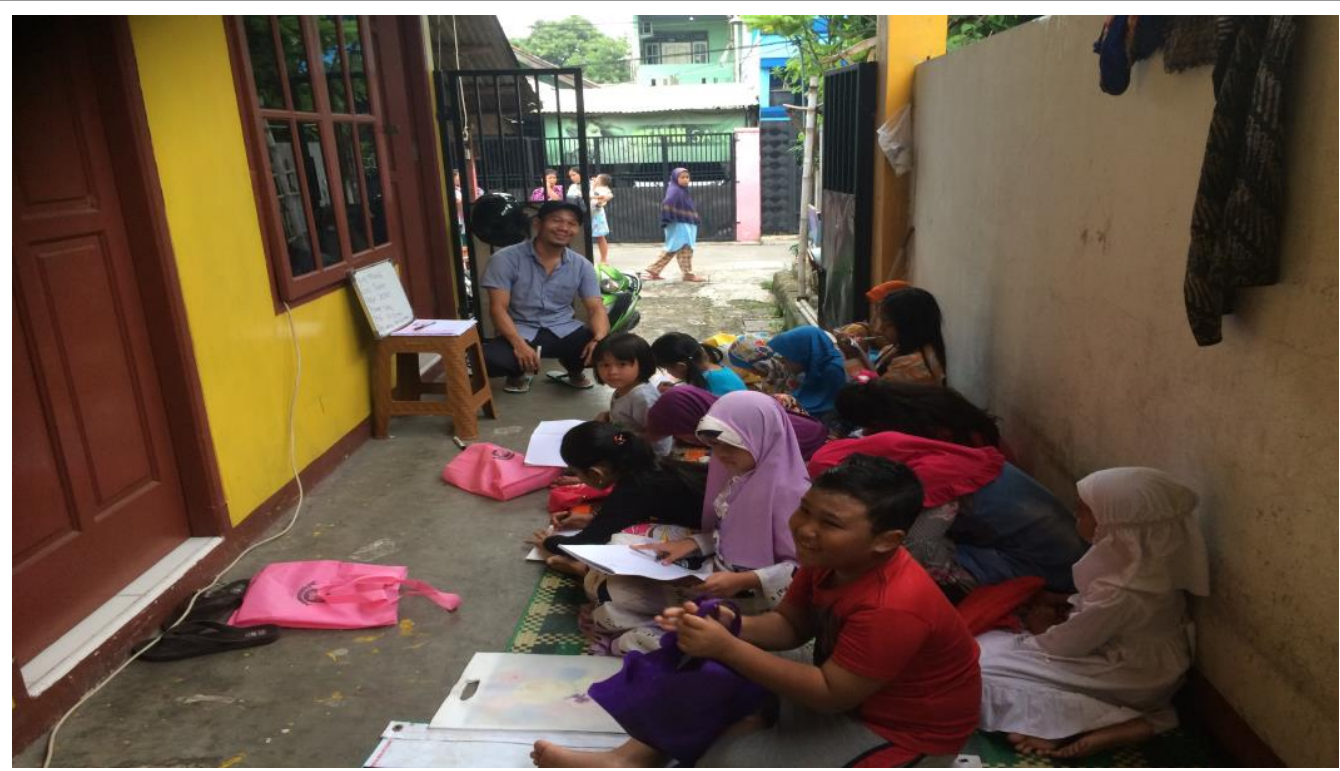

Gambar 2. Pelaksana PkM memberikan pelatihan pelafalan bunyi dasar bahasa Inggris (Alfabet A-Z)

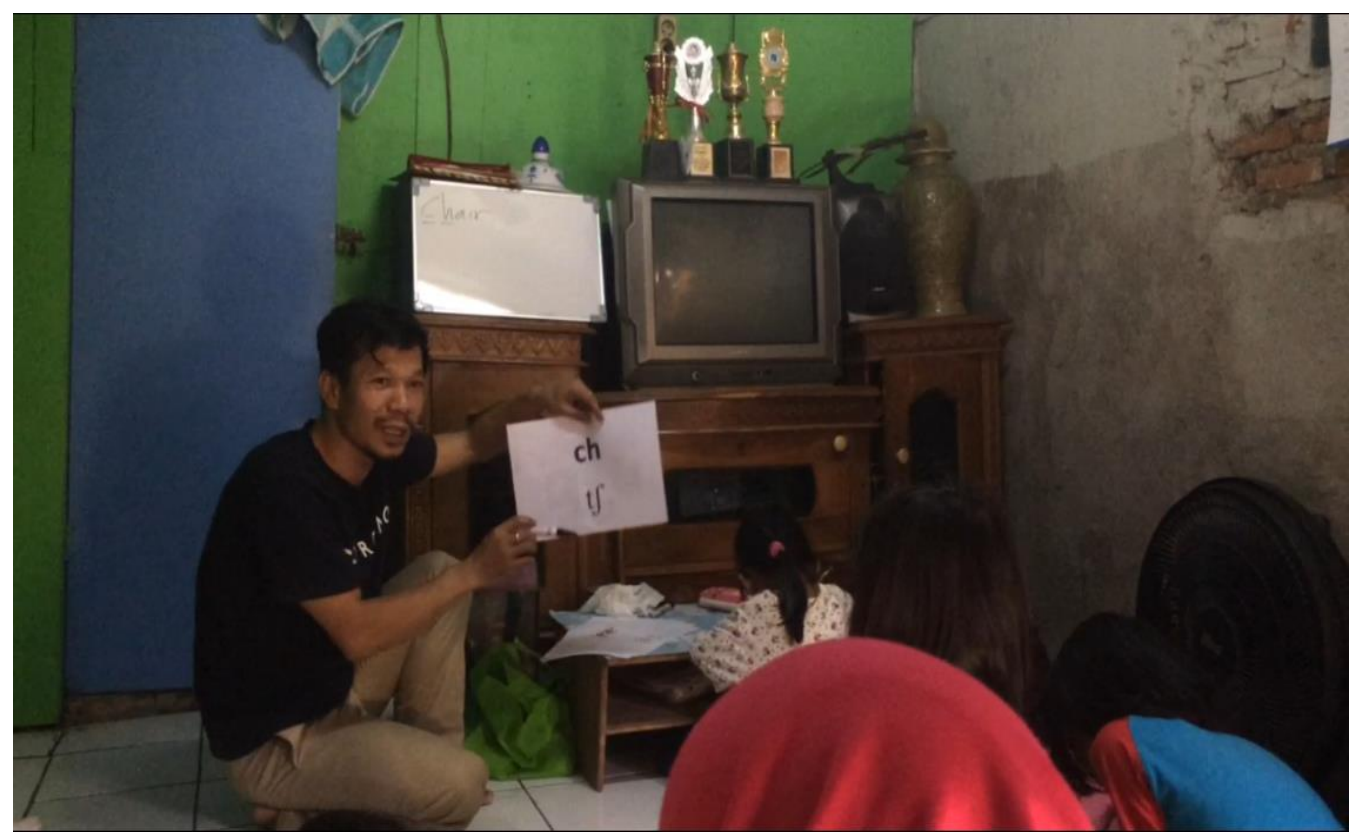

Gambar 3. Pelaksana PkM memberikan pelatihan bunyi bahasa Inggris yang unik melalui gambar simbol bunyi dan menirukan bunyinya di hadapan para peserta PkM

\section{Kesimpulan}

1. Proses belajar mengajar berlangsung dengan baik. Peserta PkM yakni anak-anak di wilayah RT.07/07 kelurahan Warakas, kecamatan Tanjung Priok, Jakarta Utara berjumlah kurang lebih tiga puluh (30) anak yang sangat aktif dan merespon materi yang diajarkan oleh pengajar. Siswa/i sangat senang dengan pelatihan bunyi kosa-kata dasara bahasa Inggris yang cocok dengan usia mereka dan yang diberikan oleh pengajar di setiap awal PkM yang bertemakan pelatihan komunikasi bahasa Inggris.

2. Dalam proses pelatihan, pengajar tidak mendapati perbedaan yang terlalu mencolok dalam hal kemampuan daya tangkap siswa/i menerima materi yang diberika pengajar.

3. Perilaku anak-anak yang kadang merengek, kesal, berantem, dan saling berebutan saat ada kuis permainan (game) yang diberikan pengajar di setiap akhir sesi pelatihan 
mengajar adalah wajar dikarenakan usia mereka yang masih anak-anak yakni berusia 6 sampai dengan 12 tahun.

4. Kegiatan PKM (Pengabdian Kepada Masyarakat) seperti ini sangat perlu dilakukan dan juga dikembangkan mengingat perlunya kemampuan bahasa asing khususnya bahasa Inggris bagi para anak-anak sekolah dasar.

5. Adanya persiapan yang lebih matang untuk para pengajar (pelaksana PKM) dalam menyesuaikan materi ajar dengan kelompok usia peserta didik. Dalam hal ini, pengajar/pelaksana PKM mempersiapkan, mengelompokkan, dan merancang materi ajar yang menarik khususnya kepada para siswa Sekolah Dasar mengingat anak-anak seusia mereka memang sangat tertarik dengan dunia bermain. Oleh karena itu, pengajar diharapakan dapat menyusun materi ajar dan juga penyajian materi dengan sangat menarik agar para peserta antusias dan cepat menyerap materi yang diajarkan kepada mereka.

6. Selain di Sekolah Dasar, ruang lingkup PKM dapat juga dikembangkan ke jenjang Sekolah Menengah Pertama (SMP), an juga Sekolah Menengah Atas/Kejuruan (SMA/SMK) karena setiap tingkat sekolah berbeda pula keterampilan, pengetahuan, dan ilmu yang mereka inginkan khususnya keinginan untuk meningkatkan nilai akademis mereka dalam mata pelajaran Bahasa Inggris.

\section{Daftar Pustaka}

Alkhuli, M. A. (1983). English as a Foreign Language. Ph.D Dissertation, King Abdul Aziz Public Library.

Daft, Richard. L. (2003). Manajemen Sumber Daya Manusia. Jakarta : Penerbit Erlangga.

Departemen Pendidikan Nasional. (2004). Kurikulum 2004 Standar Kompetensi Mata pelajaran Bahasa dan sastra Indonesia Sekolah Menengah Pertama dan Madrasah Tsanawiyah. Jakarta: Depdiknas.

Griffin, Moorhead. (2013). Perilaku Organisasi ( manajemen sumber daya manusia dan organisasi). Edisi 9. Salemba Empat.

International Phonetic Association. (1999). Handbook of the International Phonetic Association: A Guide to the Use of the International Phonetic Alphabet. Cambridge University Press.

Moosa, M. H. (1979). Difficulties of Learning the Pronunciation and Structural Differences Between Arabic andEnglish. MA Dissertation, Library of Saudi Arabia, Educational mission; Texas.

O'Connor, J. D. (1980). Better English Pronunciation (2nd ed.). Cambridge: Cambridge University Press.

Power, T. (2003). Practice for Arabic Language Background. Retrieved September 2, 2020, from http :// www.btinternet. com.

Swan, M., \& Smith, B. (2001).Learner English: A Teacher's Guide to Interference and Other Problems.Cambridge: Cambridge University Press.

Tambunsaribu, G. (2019). Say It - Keunikan Bunyi Bahasa Inggris. Deepublish. ISBN 978623-02-0336-7. Retrieved from: http://repository.uki.ac.id/2109/3/SAYITKeunikanBunyiBahasaInggris.pdf

Tambunsaribu, G. (2020). Analisis Pelafalan Mahasiswa Dalam Melafalkan Irregular Verbs Bahasa Inggris. Journal of Language and Literature, 7(2), 99-112.

Yule, G. (1996). The Study of Language (2nd ed.). Cambridge: Cambridge University Press. 